\title{
Introducing the Supporting Students with Disabilities Series: Disability Legislation Update
}

\author{
Emma Jane Wright \\ School of Sociology and Social Policy \\ University of Nottingham \\ emma@accessingmaterials.org.uk
}

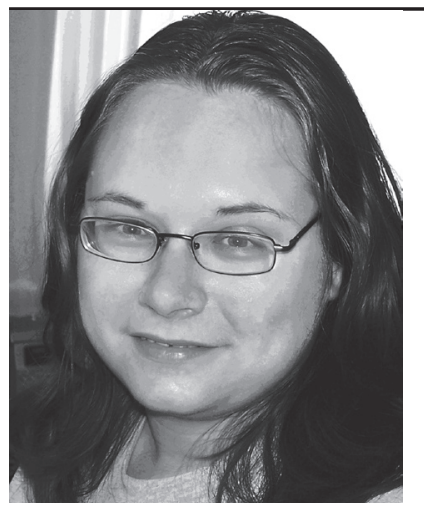

Peter James Rowlett

School of Computing and Informatics Nottingham Trent University peter.rowlett@ntu.ac.uk

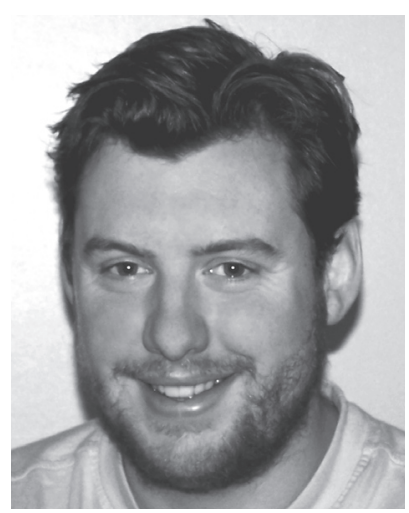

The Disability Discrimination Act (DDA) 1995 and amendments such as SENDA require teaching and learning to be made accessible to all, regardless of disability or impairment. In 2005 and 2006, amendments to this Act have changed the legal requirements for Universities (and others). As a result, Universities have a greater obligation to an increased range of students with respect to their disabilities.

For some years MSOR Connections has included a series of articles called "DDA Update". The following article, which aims to give an idea of the recent amendments to the DDA 1995, is designed to round off the DDA Update series and herald a new series of articles with an explicit focus on supporting students with disabilities.

The aim of this series of articles is to explore what institutions and individuals are doing to support students with disabilities in MSOR. This need not be related to the legislation (it is certainly the case that the legal requirement for supporting students with disabilities is not the prime motivator for some people). This sharing of good practice within the community will benefit greatly students with disabilities and, in turn, all students.

If you have an experience you would like to share, a method or tool which has helped you or a tutorial or technique you feel others might benefit from, please contact the editors (editors@mathstore.ac.uk).

\section{Disability Legislation Update}

Until recently, the main pieces of legislation affecting higher education in relation to students with disabilities were the Disability Discrimination Act (DDA) 1995, and the Special Educational Needs and Disability Act (SENDA) 2001. SENDA 2001 essentially amended Part 4 of the DDA 1995 to deal more comprehensively with issues related to education, which was only touched upon in the earlier legislation. Since then, two major new pieces of legislation have received royal ascent - the Disability Discrimination Act 2005 (which becomes Part 5a of DDA 1995) and the Disability Discrimination Act 1995 (Amendment) (Further and Higher Education) Regulations 2006. Between them, these pieces of legislation make numerous changes to the law relating to students with disabilities and higher education. This article aims to give a refresher in some parts of the legislation with a particular emphasis on the recently amended parts.

\section{Definition of Disability}

Whilst the definition of disability remains that, "a person has a disability for the purposes of this Act if he has a physical or mental impairment which has a substantial 
and long-term adverse effect on his ability to carry out normal day-to-day activities" (DDA 1995, Section 1), section 18 of DDA 2005 amends the definition, stating that, "a person who has cancer, HIV infection or multiple sclerosis is to be deemed to have a disability, and hence to be a disabled person," and this from the point of diagnosis (DDA 2005, Section 18). It also removes the requirement that, "mental illness must be clinically well-recognised if it is to be basis of 'mental impairment"' (DDA 2005, Section 18).

Thus more people are now covered under the new definition of disability. Particularly important to note is that widened still further is the range of students who are covered by the legislation who do not have an obvious disability.

\section{Duties on Public Authorities}

Section 3 of the DDA 2005 also imposes a general duty on public authorities, including Higher Education Institutions, requiring that:

"(1)Every public authority shall in carrying out its functions have due regard to -

(a) the need to eliminate discrimination that is unlawful under this Act;

(b) the need to eliminate harassment of disabled persons that is related to their disabilities;

(c) the need to promote equality of opportunity between disabled persons and other persons;

(d) the need to take steps to take account of disabled persons' disabilities, even where that involves treating disabled persons more favourably than other persons;

(e) the need to promote positive attitudes towards disabled persons; and

(f) the need to encourage participation by disabled persons in public life."

(DDA 2005, Section 3).

Institutions have a requirement to produce a Disability Equality Scheme which shows how they intend to fulfil the above requirements. By December 2006 your institution ought to have published (and you can read) this.

\section{Types of Discrimination}

Since the implementation of the DDA 1995 (Amendment) (Further and Higher Education) Regulations on 1st September 2006, there are now four forms of unlawful disability discrimination:

\section{Direct discrimination}

This is discrimination in which a disabled person is treated less favourably, for example, excluded from a part of the education process, due to their disability.

\section{Failure to comply with a duty to make reasonable adjustments}

Previously, education providers were required to make reasonable adjustments to services (including, e.g. teaching) to ensure students with disabilities are not treated less favourably.

The new amendments extend this to require that these include, "positive steps to ensure that disabled people can access education and related services," and stress that, "this goes beyond simply avoiding treating disabled people less favourably and in some cases may also mean taking additional steps to which non-disabled people are not entitled" (DRC, 2006, para. 5.2).

Reasonable adjustments may take a number of forms; examples are facing the class when talking to allow a deaf student to lip-read and providing a reading list several months in advance of the start of a module to allow time for materials to be converted into Braille for a blind student. Of course, these kinds of steps should be taken in anticipation of students requiring these adjustments, and not simply when you are made aware of a specific need in your institution.

\section{Victimisation and harassment}

The victimisation provision is to protect people involved in a claim under the DDA. This is relevant, if a person with a disability who makes a claim, or a person who supports that claim (with or without a disability) (e.g., by acting as a witness) is victimised by the institution as a result. The harassment provision protects a disabled person from behaviour which violates their dignity or creates "an intimidating, hostile, degrading, humiliating or offensive environment" (DRC, 2006, para 7.13). This is relevant whether or not the behaviour is intended as such; an example is that staff making jokes in private at the expense of a disabled person due to their disability is unlawful.

\section{Disability-related discrimination}

Disability-related discrimination differs from direct discrimination in that the latter is discrimination because a person is disabled, while the former is discrimination based on the effect of a disability. For example, discrimination on the grounds that a person has cerebral palsy is direct discrimination, whilst discrimination on the basis that a person writes slowly because of their cerebral palsy is disability-related.

\section{Further information}

The new code of practice for providers of post- 16 education provides guidance on the legislation and examples to support this, including examples of the forms of unlawful disability discrimination (DRC, 2006).

Students should be directed towards the DRC's "A Guide for Disabled Students and Learners". 


\section{References}

1. Disability Discrimination Act 1995, c. 50.

2. Disability Discrimination Act 2005, c. 13.

3. Disability Discrimination Act 1995 (Amendment) (Further and Higher Education) Regulations 2006, SI 2006, No. 1721.

4. Disability Rights Commission (2006) Code of Practice for Providers of Post-16 Education. Accessed via http:// www.drc.gov.uk/library/publications/education/code_ of_practice_post_16_educ.aspx (14 October 2006).

5. DRC (2006) A Guide for Disabled Students and Learners. Accessed via http://www.drc.gov.uk/library/ publications/education/a_guide_for_disabled_student. aspx (14 October 2006).

6. Disability Rights Commission: http://www.drc.gov.uk/

\section{The Supporting Students with Disabilities Series, supported and published by the Maths, Stats \& OR Network, aims to explore what institutions and individuals are doing to support students with disabilities in MSOR. \\ If you have an experience you would like to share, a method or tool which has helped you or a tutorial or technique you feel others might benefit from, please contact the editors (editors@mathstore.ac.uk). \\ The Maths, Stats and OR Network maintains a list of articles, reports and useful links relating to Access Issues, at: www.mathstore.ac.uk/access}

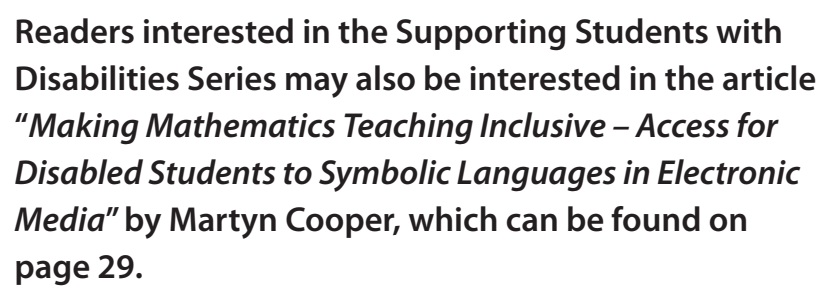

Readers interested in the Supporting Students with Disabilities Series may also be interested in the article "Making Mathematics Teaching Inclusive - Access for Disabled Students to Symbolic Languages in Electronic Media" by Martyn Cooper, which can be found on page 29.

\section{Certificate in Teaching Statistics in Higher Education}

Prepared by the statistics team of the UK Higher Education Academy (HEA), Mathematics, Statistics and OR Network, this six-section course on Teaching Statistics in HE is offered for distance learning study by university or HE staff teaching, or about to teach, statistics at university or HE level. It has been accredited as a Certificate qualification by the Royal Statistical Society and for Associateship of the UK HEA.

The course can be taken in various modes:

- as a one-year external distance-learning Certificate in Teaching Statistics in HE;

- as a single (possibly optional) unit in a university PgCert or Diploma in Learning and Teaching;

- as an ad hoc distance-learning programme with components of study chosen to suit individual needs: both for initial training and continuing professional development.

Full documentation, tutorial support and assessment will be provided. We are now moving into the fourth year of this highly successful course. As the course is no longer subsidised by the HEA, in the year 2006-2007, the fee for the full course will be $£ 850$ per participant. The Certificate in Teaching Statistics in HE is accredited by the Royal Statistical Society. For self-study, review or trial by a university or HE department, a fee of $£ 300$ will apply.

For more details, potential participants or representatives of staff development units should contact:

The Centre Administrator,

Royal Statistical Society Centre for Statistical Education, School of Computing and Informatics,

Nottingham Trent University, Clifton Lane, Clifton, Nottingham NG11 8NS. UK

Email: alison.davies2@ntu.ac.uk or The Course Leader: Dr John Marriott (john.marriott@ntu.ac.uk)
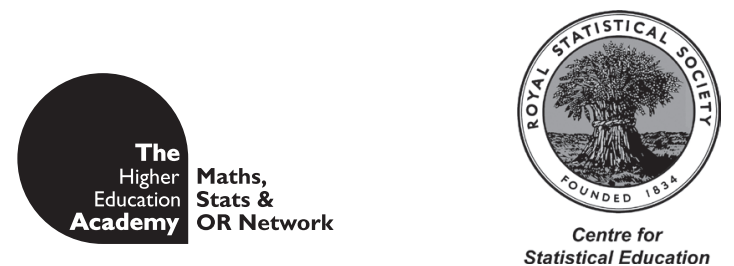